\title{
Correspondence
}

\section{Reuse of syringes in anaesthesia practice}

\section{To the Editor:}

Anaesthetists have felt secure in reusing syringes from patient to patient as long as needles were changed and the solution had not obviously been contaminated with blood. Over the last decade, this practice has become less common. Many feel that injecting a drug, at the port most distant from the patient in an intravenous line will guarantee the syringe contents to be free of contamination. However, the contamination rate with blood is between $3.3 \%$ and $0.3 \%$ depending on the distance of the port from the catheter. ${ }^{1}$ The presence of the one way valve in the administration set will in most instances prevent back flow of blood from the patient to the most distant port. However, the competence of the one way valve cannot be guaranteed, as demonstrated by Crosby while injecting propofol. ${ }^{2}$ Only minimal contamination with blood to transmit viral disease. ${ }^{1}$

The contents of a refilled syringe cannot be guaranteed to be free of contamination. ${ }^{3}$ Health Canada in August 1994 stated that the practice of using single use low osmolar dye intravenous delivery systems on more than one patient is potentially unsafe. ${ }^{4}$ I suggest that the reuse of syringes in anaesthesia is analogous and should be subject to this advisory notice.

There is a small but finite risk of nosocomial infection from reuse of syringes and infusions. It is difficult, if not impossible, to trace an infection with a long latent period (i.e., hepatitis B, hepatitis C, HIV) to an anesthetic some weeks or months previously. Cost containment and convenience do not justify reuse of syringes.

Gary B. Skidmore MD FRCPC

Department of Anaesthesia,

Faculty of Medicine

University of Ottawa

501 Smyth

Ottawa, Ontario K1H 8L6

\section{REFERENCES}

1 Trépanier CA, Lessard MR, Brochu JG, Denault PH. Risk of cross-infection related to the multiple use of disposable syringes. Can J Anaesth 1990; 37: 156-9.

2 Crosby ET. Intravenous infusions and one-way valves (Letter). Can J Anaesth 1991; 38: 799-800

3 Blogg CE, Ramsay MA, Jarvis JD. Infection hazard from syringes. Br J Anaesth 1974; 46: 260-2.

4 Canada Communicable Disease Report, Vol. 20-16, August 30, 1994.

\section{Postoperative pain in children}

To the Editor:

We enjoyed the article by Wong et al. on the management of post-tonsillectomy pain in children. ${ }^{1}$ Most paediatric anaes- thetists find the usual analgesic regimens less than satisfactory for this common procedure. The results indicate that, in comparison with placebo or bupivacaine spray, infiltration of bupivacaine with epinephrine produced less pain (by pain score) on first awakening after anaesthesia, and that the effect lasted less than an hour. However, we are concerned that an opportunity to identify a greater response to their intervention may have been missed by their failure to use an adequate measure of pain following initial recovery.

The "Objective Pain Scale" of Norden et al. ${ }^{2}$ assesses both behaviour and physiological changes (heart rate and blood pressure). It has been used in a number of studies of children's postoperative pain, but has never had peer-reviewed evaluation of its reliability or validity. It is, however, very similar to the Children's Hospital of Eastern Ontario Pain Scale (CHEOPS), ${ }^{3}$ and at least one study found no differences between them. ${ }^{4}$ The CHEOPS has been shown to be valid and reliable for immediate postoperative pain, but becomes less useful for pain lasting more than an hour or so, as "pain behaviours" habituate with time. ${ }^{5}$ It would have been appropriate to use a self-report measure of pain for many of the children in this study (such as the Faces scale of Bieri et al. ${ }^{6}$ ), which might have shown a difference in pain scores beyond the immediate recovery phase and allowed the authors to glean more information from their research.

The greatest challenges in paediatric pain management result from difficulties in assessment and measurement, not from the complexities of pharmacology. It is critical that we understand the assumptions and implications of our measurement tools in this field, just as in any other scientific investigation.

G. Allen Finley MD FRCPC

Patrick J. McGrath PhD

Departments of Anaesthesia and Psychology

Dalhousie University

IWK Children's Hospital

Halifax, NS B3J 3G9

\section{REFERENCES}

1 Wong AK, Bissonnette B, Braude BM, Macdonald RM, St-Louis PJ, Fear DW. Post-tonsillectomy infiltration with bupivacaine reduces immediate postoperative pain in children. Can J Anaesth 1995; 42: 770-4.

2 Norden J, Hannallah R, Getson P, O'Donnell R, Kelliher $G$, Walker $N$. Reliability of an objective pain scale in children. Anesth Analg 1991; 72: S199.

3 McGrath PJ, Johnson G, Goodman JT, Schillinger J, Dunn J, Chapman J. The CHEOPS: A behavioral scale to measure post operative pain in children, $I n$ : Fields HL, Dubner R, Cervero F (Eds.). Advances in Pain Research and Therapy, New York: Raven Press, 1985: 395-402.

4 Norden J, Hannallah $R$, Getson $P, O^{\prime}$ Donnell $R$, Kelliher $G$, Walker $N$. Concurrent validation of an objective pain scale for infants and children. Anesthesiology 1991; 75: A934.

5 Beyer J, McGrath PJ, Berde C. Discordance between self 